\title{
MOBILE-BASED OUTPATIENT QUEUE SYSTEM \\ USING THE PRIORITY SCHEDULING AND FIRST COME FIRST SERVED SCHEDULING METHOD
}

\author{
Anton Setiawan $\mathrm{H}^{1}$, Dwi Nugraheny ${ }^{2}$, Saprudin ${ }^{3}$ \\ Program Studi Teknik Informatika \\ Sekolah Tinggi Teknologi Adisutjipto Yogyakarta \\ informatika@stta.ac.id ${ }^{1}$, henynug@gmail.com², Saprudinese@gmail.com³
}

\begin{abstract}
The outpatient queue system at the Pratama Clinic still uses manuals so that it can implement computerized technology (mobile) to improve health services for patients. In making this outpatient queue system application using the Priority Scheduling method which is a priority scheduling algorithm. Each process is equipped with a priority number (the smallest integer value is usually the biggest priority). This outpatient queue system is mobile based with the aim that patients can register online. Test results using a comparison of smartphones from the Android 4.1 version of Jelly Bean to the Android 7.0 version of Nougat can run. Comparison of distances in applications with google maps, get the same results and test application users using a questionnaire that is calculated with a Likert Scale to get $81.8 \%$ results including the "Very Good" category.
\end{abstract}

Keywords: Mobile, Priority Scheduling, First Come First Served Scheduling, Queue System.

\section{Latar Belakang Masalah}

Kemajuan teknologi informasi telah mempengaruhi gaya hidup masyarakat masa kini. Khususnya masyarakat perkotaan dimana sarana dan prasarana sudah memadai. Oleh karena itu bukan menjadi penghalang untuk menerapkan teknologi terkini dalam mendukung kinerja disuatu institusi atau lembaga. Demikian juga sebuah klinik yang melayani pasien rawat jalan, tentu membutuhkan bantuan teknologi berbasis mobile khususnya Android untuk mempermudah proses pelayanan kepada pasiennya.

Android adalah salah satu platform sistem operasi yang digemari masyarakat karena sifatnya yang open source sehingga memungkinkan pengguna untuk melakukan pengembangan. Android merupakan generasi baru platform mobile berbasis linux yang mencakup sistem operasi, middleware, dan aplikasi untuk digunakan diberbagai macam perangkat smartphone, [1].

Pada beberapa klinik pengobatan dan kesehatan seperti Klinik Pratama, untuk mendapatkan pelayanan, pasien biasanya harus mendaftar terlebih dahulu agar mendapatkan kartu berobat. Selanjutnya pasien yang sudah mendaftar akan mendapatkan nomor antrian sesuai dengan urutan pada pendaftaran pelayanan pasien. Jika jumlah pasien yang berobat banyak, maka antrian pasien yang akan dilayani juga akan semakin panjang.

Antrian dengan metode Priority Scheduling merupakan algoritma penjadwalan berprioritas. Tiap - tiap proses dilengkapi dengan nomor prioritas (nilai integer terkecil biasanya merupakan prioritas terbesar). Pengerjaan mendahulukan proses yang memiliki prioritas terbesar. Jika beberapa proses memiliki prioritas yang sama, maka akan digunakan algoritma First Come First Served Scheduling (FCFS). Jika ada suatu proses yang baru 
datang memiliki prioritas yang lebih tinggi dari pada proses yang sedang dijalankan, maka proses yang sedang berjalan tersebut dihentikan, lalu dialihkan untuk proses yang baru datang tersebut [2]. Sementara itu, pada non-preemptive, proses yang baru datang tidak dapat mengganggu proses yang sedang berjalan, tetapi hanya diletakkan di depan queue.

Berdasarkan penjelasan di atas, maka tujuan penelitian ini adalah merancang bangun sistem berbasis mobile untuk memberi kemudahan bagi pasien mendaftar berobat secara online melalui skala prioritas.

Skala Prioritas dimaksudkan seberapa beratnya kondisi pasien untuk didahulukan dalam menerima layanan pengobatan. Sehingga digunakan metode antrian Priority Scheduling dan First Come First Served Scheduling (FCFS)

\section{Metodologi Penelitian}

Metodologi penelitian yang digunakan untuk penyelesaian masalah pada penelitian ini adalah:
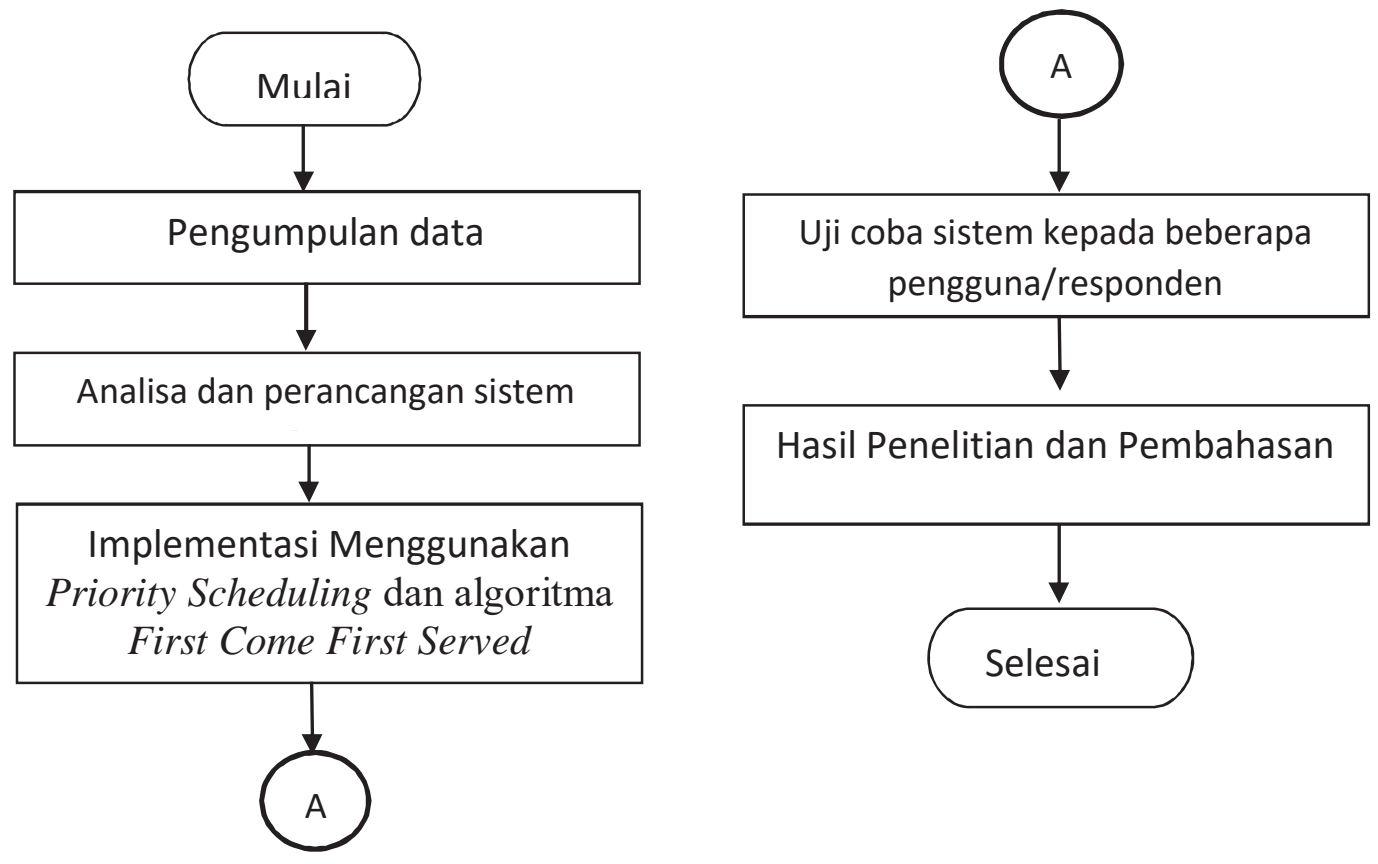

Gambar 1. Diagram alir metodelogi penelitian

a. Pengumpulan Data

Pengumpulan data dilakukan melalui membaca buku-buku referensi materi khususnya metode dan algoritma yang digunakan pada sistem yang akan dibangun dalam penelitian ini. Melakukan wawancara pada salah satu karyawan yang berwenang di klinik Pratama untuk mengetahui masalah yang sering timbul dalam menangani para pelanggan/pasien dalam mendapatkan layanan pengobatan.

b. Analisa dan Perancangan Sistem.

Analisa dilakukan guna mengetahui perangkat-perangkat pendukung yang dibutuhkan secara fungsional dan non fungsional, konsep metoda dan algoritma. Perancangan sistem dibuat untuk menentukan data-data variabel, konsep sistem, aliran sistem dan aliran data-data agar dapat berjalan dengan benar, sesuai dengan tujuan yang ingin dicapai. 
c. Implementasi Menggunakan Priority Scheduling dan algoritma First Come First Served.

Implementasi sistem yakni melakukan pengkodean dari rancangan sistem yang telah dibuat menggunakan Priority Scheduling dan algoritma First Come First Served.

d. Uji coba sistem kepada beberapa pengguna/responden.

Setelah sistem diimplementasikan, kemudian dilakukan uji coba kepada 10 pengguna/responden pasien, 15 pengguna/responden umum (rekan dosen dan mahasiswa) serta 8 kepada petugas klinik Pratama. Uji coba sistem ini untuk mengetahui apakah sistem telah berjalan sesuai rancangan dan tujuan.

\subsection{Algoritma Penjadwalan}

Menurut [2] masalah penjadwalan CPU (Central Processing Unit) adalah memutuskan proses mana yang berada di dalam antrian ready akan dialokasikan ke CPU. Ada beberapa algoritma penjadwalan CPU beberapa diantaranya akan di jelaskan pada bagian berikut ini.

- Penjadwalan dengan prioritas

Priority Scheduling merupakan algoritma penjadwalan yang mendahulukan proses dengan nilai prioritas tertinggi. Setiap proses memiliki prioritasnya masing-masing. Prioritas suatu proses dapat ditentukan melalui beberapa karakteristik antara lain:

a. Batas waktu

b. Kebutuhan memori

c. Akses file

d. Tingkat kepentingan proses

Kelemahan pada penjadwalan prioritas adalah dapat terjadinya indefinite blocking (starvation) yaitu suatu proses dengan prioritas yang rendah memiliki kemungkinan untuk tidak dieksekusi jika terdapat proses lain yang memiliki prioritas lebih tinggi darinya. Solusi dari permasalahan ini adalah aging, yaitu meningkatkan prioritas dari setiap proses yang menunggu dalam antrian secara bertahap, [2].

\section{- First-Come First-Served (FCFS)}

Algoritma ini merupakan algoritma penjadwalan yang paling sederhana yang digunakan CPU. Dengan menggunakan algoritma ini seiap proses yang berada pada status ready dimasukkan ke dalam antrian FCFS sesuai dengan waktu kedatangannya. Proses yang tiba terlebih dahulu yang akan dieksekusi terlebih dahulu, [3].

\subsection{Perancangan Desain Jaringan Komputer}

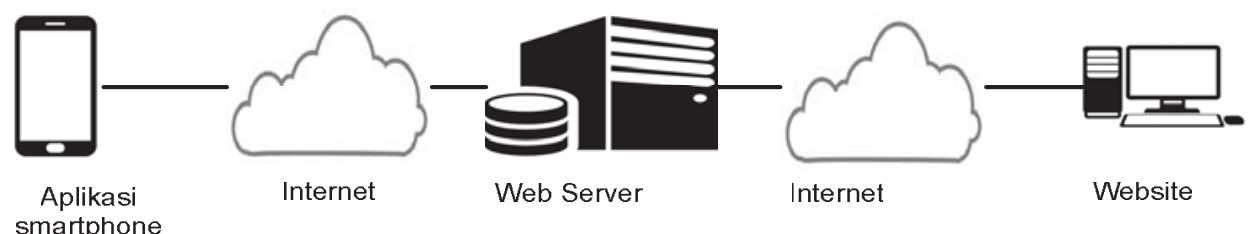

Gambar 2. Skema antrian rawat jalan di klinik 
Gambar 2 merupakan skema pengambilan data pasien, lokasi pasien dan data nomer antrian pada smartphone android yang memiliki fasilitas GPS (Global Positioning System) dan memiliki koneksi jaringan internet. Setelah itu smartphone berfungsi untuk mengrim data melalui jaringan internet. Internet ini berfungsi sebagai jalur pengiriman data dari smartphone ke web server. Selanjutnya web server berfungsi untuk menyimpan data pasien dan antrian yang sudah diterima dari smrtphone melalui jaringan internet. Website berfungsi untuk memproses data antrian pada pasien, kelola pasein, kelola jadwal praktek dan kelola admin dari web server melalui jaringan internet serta menampilkan data yang sudah diambil web server.

\subsection{Perancangan Flowchart pada Sistem Rawat Jalan}

Flowchart (alur data) merupakan alur kerja atau prosedur-prosedur dimulai dari pasien melakukan daftar pasien jika belum daftar klik pada daftar. Pada form daftar pasien ini pasien harus mengisi form sampai selesai, jika sudah selesai klik tombol daftar. Jika pasien sudah daftar, maka masuk login untuk dapat masuk ke dalam system melalui validasi terlebih dahuludengan cara memasukkan username dan password. Apabila username dan password salah, maka akan kembali ke menu login. Jika username dan password benar, maka proses selanjutnya akan lanjut ke menu Sistem antrian rawat jalan pada klinik Pratama. Alur secara keseluruhan dapat dilihat pada Gambar 3.

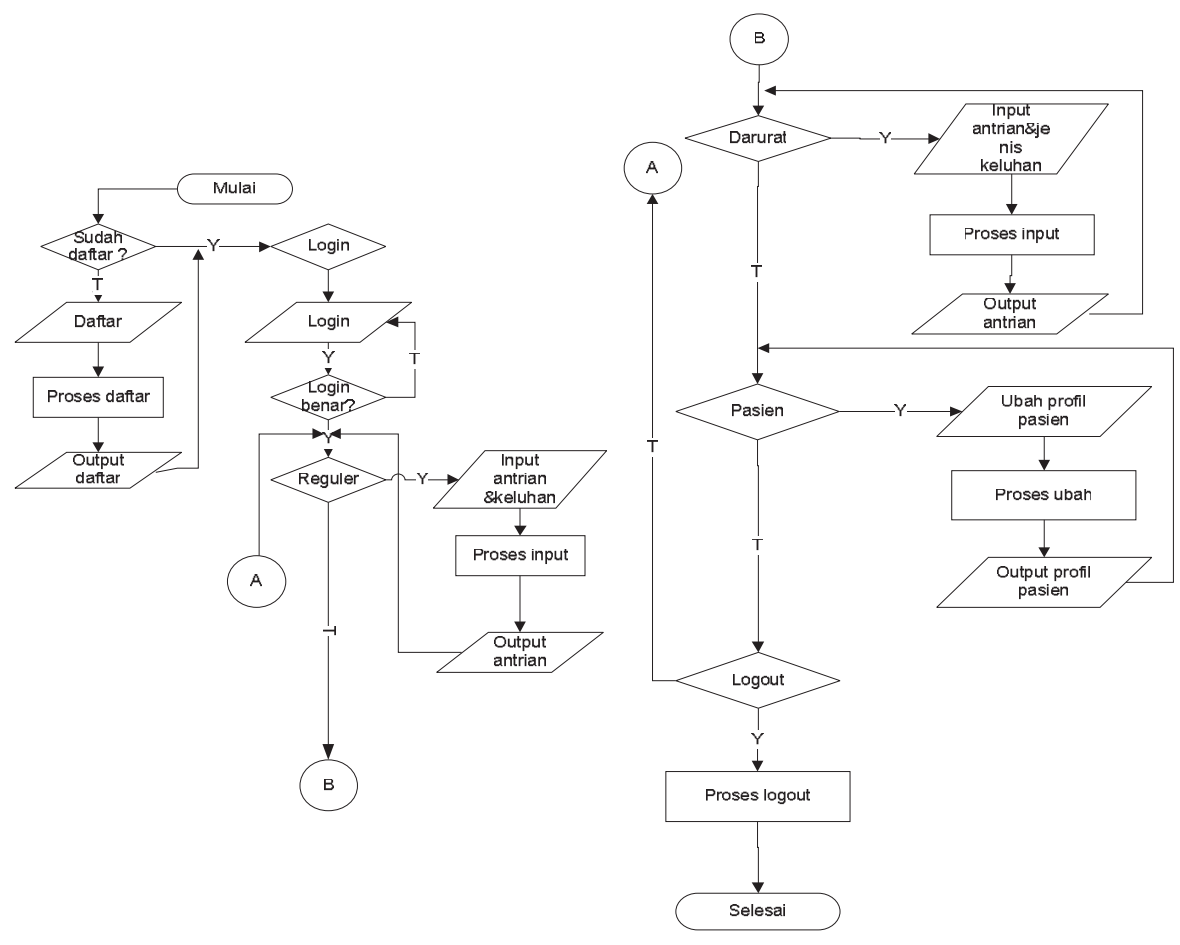

Gambar 3. Flowchart Sistem Penjadwalan Pasien berbasis mobile

\subsection{Context Diagram}

Context diagram dalam penelitian ini pada Gambar 4 menggunakan 2 (dua) entiti yaitu Admin dan Pasien. Admin berfungsi mengentri, meng-update, serta menambah data 
tentang antrian jadwal pasien. Sedangkan Pasien sebagai pengguna aplikasi antrian jadwal pasien.

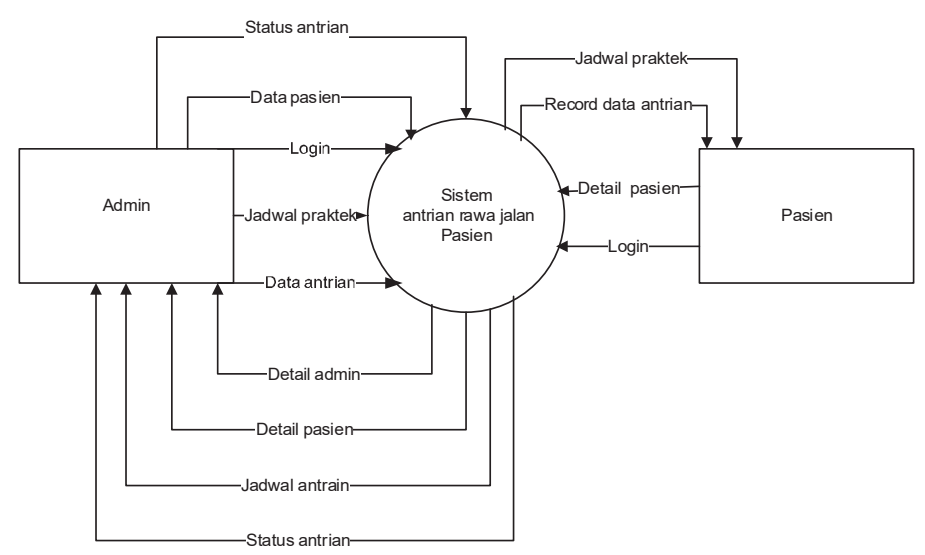

Gambar 4. Context Diagram Sistem Penjadwalan Pasien berbasis mobile

Pada Gambar 4, sebagai Admin adalah salah satu petugas pada klinik Pratama untuk dapat mengentri dan meng-update data-data penjadwalan dan data pasien lama. Sedangkan Pasien mengentri login dan data pasien berupa identitas dan jenis keluhan. Sehingga sistem nantinya dapat mengolah data-data pasien yang masuk dengan Priority Scheduling dan algoritma First Come First Served.

\section{IMPLEMENTASI DAN PENGUJIAN}

Implementasi pada sistem aplikasi dimulai dengan input login pasien sampai dengan output informasi tentang jadwal pasien seperti ditampilkan pada Gambar 5 (a), (b), (c), Gambar 5 (a), (b), serta Gambar 6. Pada form login dan form daftar pasien digunakan untuk meng-input-kan username dan password, lalu di bawahnya terdapat tombol masuk untuk login ke admin. Implemantasi daftar pasien ini merupakan halaman form daftar pasien, dimana pasien wajib mengisi kolom dengan data yang benar, jika selesai pilih tombol Daftar.

Pada Gambar 5, implementasi utama pasien pada antrian reguler ini merupakan halaman untuk daftar jadwal praktek dan didalam halaman ini ada pemberitahuan estimasi perjalanan dari tempat pasien ke klinik jika pasien ingin daftar klik tombol Daftar. Implementasi konfirmasi antrian pasien darurat ini merupakan halaman untuk konfirmasi antrian pasien agar pasien mendapatkan nomer antrian. Output informasi antrian pasien ini merupakan halaman hasil konfirmasi antrian yang menampilkan nomer antrian. 


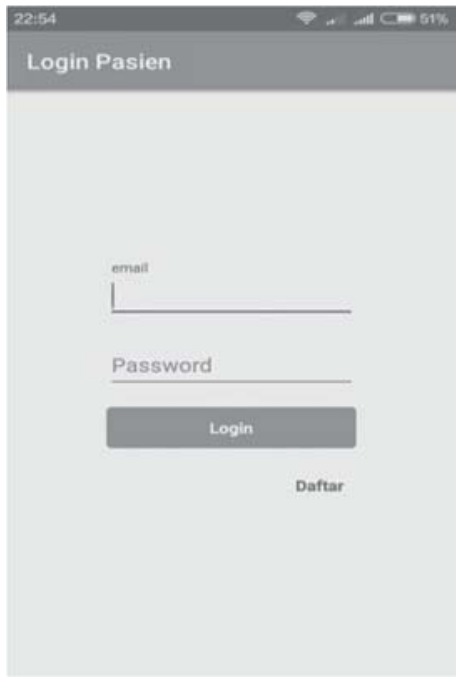

(a)

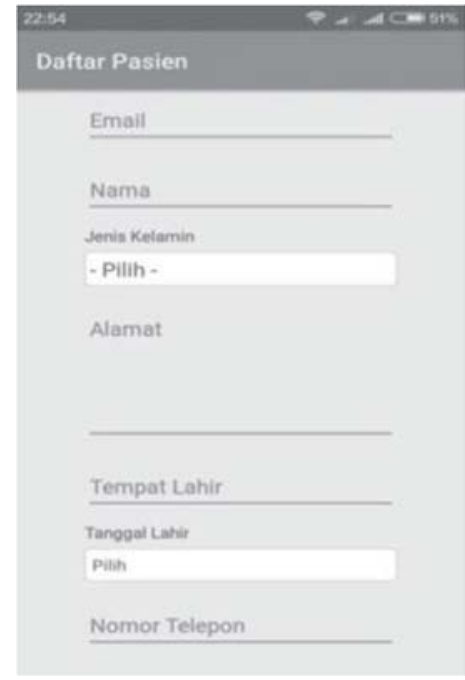

(b)

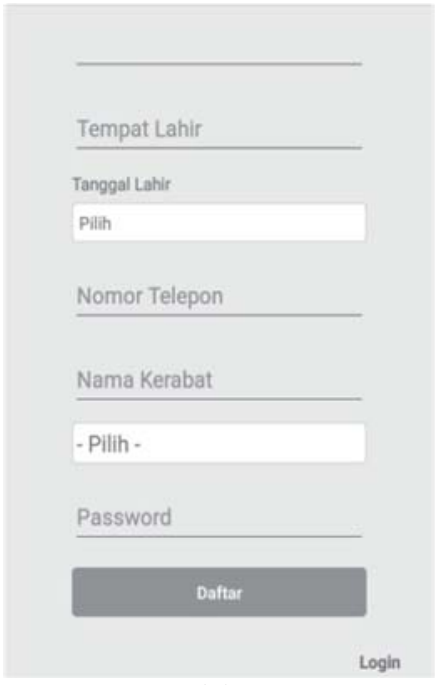

(c)

Gambar 5. Implementasi Form Login (a) dan Form Daftar Pasien (b), (c)

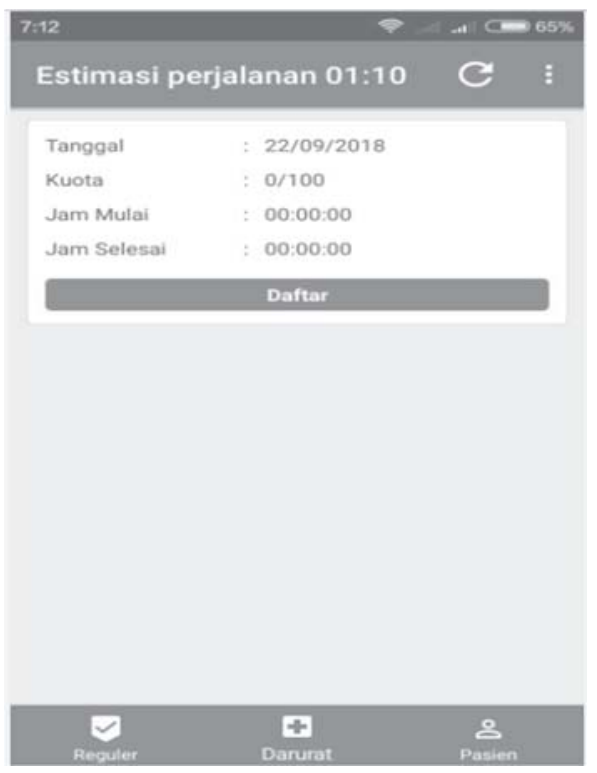

(a)

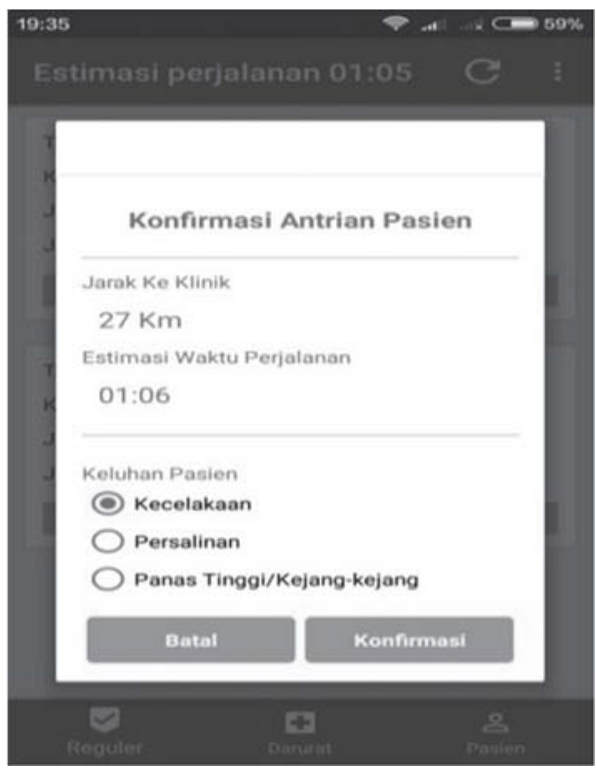

(b)

Gambar 6. Contoh Jadwal Praktek Darurat (a), dan Konfirmasi Antrian Pasien (b) 


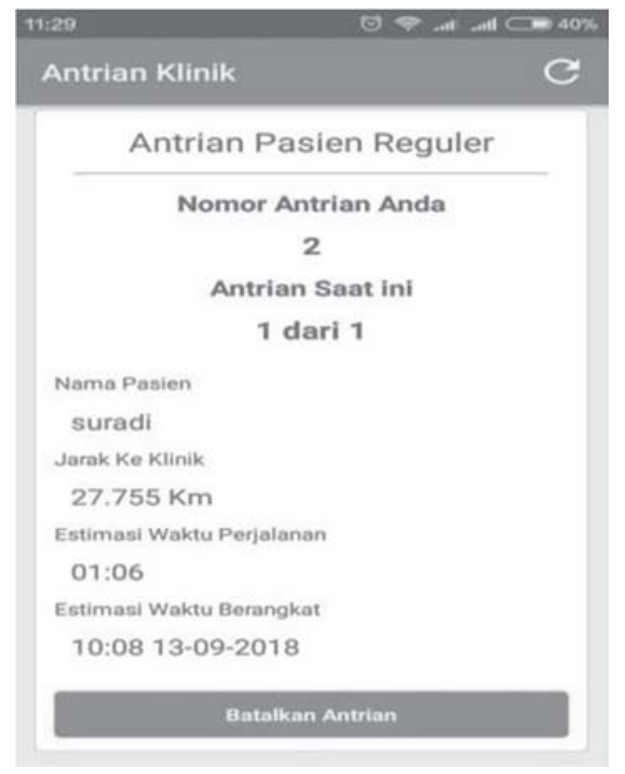

Gambar 7. Output Nomor Antrian

Uji coba pengguna Sistem Antrian Rawat Jalan pada Klinik Pratama Berbasis Mobile dengan Metode Priority Scheduling dan First Come First Served Scheduling (FCFS) dilakukan dengan menggunakan kuesioner yang dihitung berdasarkan metode Skala Likert. Dimana disetiap pernyataan memiliki 5 jawaban, dengan memberi skor pada setiap jawaban, yaitu SS (Sangat Setuju) skor 5, jawaban S (Setuju) bernilai skor 4, jawaban N (Netral) bernilai skor 3, jawaban TS (Tidak Setuju) bernilai skor 2, dan STS (Sangat Tidak Setuju) bernilai skor 1 . Untuk menentukan interval jarak dari terendah $0 \%$ hingga tertinggi $100 \%$ menggunakan rumus $1=100$ / jumlah pilihan jawaban.

Pada kuesioner ini terdiri dari 10 pernyataan dan dijawab oleh 30 responden mengenai tampilan dan kinerja dari aplikasi. Para responden tersebut 10 pengguna/responden pasien, 15 pengguna/responden umum (rekan dosen dan mahasiswa) serta 5 kepada petugas klinik Pratama. Berikut ini adalah hasil yang diperoleh dari kuesioner yang dihitung menggunakan metode skala likert.

Tabel 1. Total Hasil Perhitungan Kuesioner

\begin{tabular}{|c|c|c|c|c|c|}
\hline \multirow{2}{*}{ No } & \multicolumn{5}{|c|}{ Total Jawaban } \\
\cline { 2 - 6 } & $\begin{array}{c}\text { Sangat } \\
\text { Tidak Setuju }\end{array}$ & $\begin{array}{c}\text { Tidak } \\
\text { Setuju }\end{array}$ & Netral & Setuju & Sangat Setuju \\
\hline 1 & 0 & 1 & 2 & 17 & 10 \\
\hline 2 & 0 & 1 & 5 & 18 & 6 \\
\hline 3 & 0 & 0 & 4 & 9 & 17 \\
\hline 4 & 0 & 0 & 9 & 16 & 5 \\
\hline 5 & 0 & 0 & 6 & 12 & 12 \\
\hline 6 & 0 & 0 & 1 & 17 & 12 \\
\hline 7 & 0 & 0 & 6 & 15 & 9 \\
\hline 8 & 0 & 1 & 7 & 19 & 3 \\
\hline 9 & 0 & 0 & 7 & 18 & 5 \\
\hline 10 & 0 & 1 & 6 & 16 & 7 \\
\hline
\end{tabular}


Pada Tabel 1 merupakan hasil perhitungan kuesioner responden mengenai pengujian sistem oleh 30 responden.

- Pada perhitungan penilaian dari skor pernyataan adalah sebagai berikut, contoh penilaian pernyataan nomor 1 .
a. Sangat Tidak Setuju (skor 1 ) adalah $=0 \times 1=0$.
b. Tidak Setuju (skor 2) adalah $=1 \times 2=2$.
c. Netral (skor 3 ) adalah $=2 \times 3=6$.
d. Setuju (skor 4) adalah $=17 \times 4=68$.
e. Sangat setuju (skor 5) adalah $=10 \times 5=50$.

- Menghitung total skor dengan menjumlahkan seluruh jumlah skor penilaian. Jumlah skor pernyataan nomor $1=126$.

- Menghitung presentase pada pernyataan nomor 1 yaitu:

a. Total skor $\mathrm{x}$ 100/150 (jumlah pilihan jawaban $\mathrm{x}$ jumlah kuesioner yang telah diisi $/ 5 \times 30)$.

b. $126 \times 100 / 150=84$.

Perhitungan penilaian keseluruhan skor pernyataan dapat dilihat pada Tabel 2.

Tabel 2. Persentase Pengujian Aplikasi

\begin{tabular}{|c|c|c|c|c|c|c|c|}
\hline \multirow{2}{*}{ Pernyataan } & \multicolumn{5}{|c|}{ Penilaian } & \multirow{2}{*}{$\begin{array}{l}\text { Total } \\
\text { skor }\end{array}$} & \multirow{2}{*}{$\begin{array}{c}\text { Presentase } \\
(\%)\end{array}$} \\
\hline & STS & $\mathrm{TS}$ & $\mathrm{N}$ & $\mathrm{S}$ & SS & & \\
\hline 1 & 0 & 2 & 68 & 50 & 126 & 126 & 84 \\
\hline 2 & 0 & 2 & 15 & 72 & 30 & 119 & 79,3 \\
\hline 3 & 0 & 0 & 12 & 36 & 85 & 133 & 88,6 \\
\hline 4 & 0 & 0 & 27 & 64 & 25 & 116 & 77,3 \\
\hline 5 & 0 & 0 & 18 & 48 & 60 & 126 & 84 \\
\hline 6 & 0 & 0 & 3 & 68 & 60 & 131 & 87,3 \\
\hline 7 & 0 & 0 & 18 & 60 & 48 & 126 & 84 \\
\hline 8 & 0 & 2 & 21 & 76 & 15 & 114 & 76 \\
\hline 9 & 0 & 0 & 36 & 60 & 15 & 111 & 78,6 \\
\hline 10 & 0 & 2 & 18 & 64 & 35 & 119 & 79,3 \\
\hline \multicolumn{7}{|c|}{ Total presentase } & 818 \\
\hline \multicolumn{7}{|c|}{ Rata-rata } & 81,8 \\
\hline
\end{tabular}

Perhitungan rata-rata pada pengujian tampilan dan fungsi dari Sistem Antrian Rawat Jalan pada Klinik Pratama Berbasis Mobile dengan Metode Priority Scheduling Dan First Come First Served Scheduling (FCFS) adalah:

$$
\begin{aligned}
\text { Rata-rata } \% \quad & =\text { total presentase } / \text { total pernyataan } \\
& =818 / 10 \\
& =81,8 \%
\end{aligned}
$$

Berdasarkan Tabel 2 hasil dari rata-rata yang sudah didapat dari pengujian menggunakan kuesioner, dihitung menggunakan metode skala Likert adalah 81,8 \%, maka dapat disimpulkan bahwa pengujian aplikasi menggunakan kuisioner masuk dalam kriteria "Sangat Baik". 


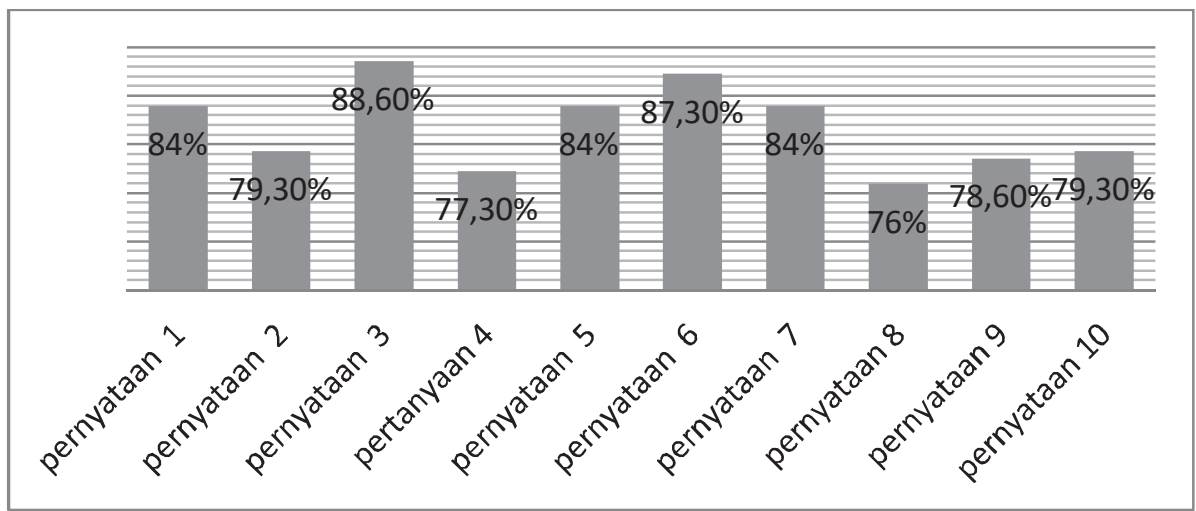

Gambar 7. Grafik Uji Pengguna

Tabel 3. Perbandingan Alur Kerja jadwal antrian pasien secara Manual dan Sistem.

\begin{tabular}{|c|c|}
\hline Manual & Sistem \\
\hline $\begin{array}{l}\text { 1. Pasien/pengguna tidak tahu informasi } \\
\text { jadwal praktek dari internet (aplikasi, } \\
\text { website). } \\
\text { 2. Pasien/pengguna tidak tahu informasi } \\
\text { kuota pasien pada jadwal praktek dari } \\
\text { internet (aplikasi, website). } \\
\text { 3. Pasien/pengguna tidak dapat daftar } \\
\text { antrian rawat jalan dari internet } \\
\text { (aplikasi, website). Sistem manual } \\
\text { tidak efisien waktu karena ketika } \\
\text { daftar antrian rawat jalan karena } \\
\text { harus datang ke klinik. } \\
\text { 4. Pasien tidak dapat bukti nomor } \\
\text { antrian rawat jalan pada klinik. } \\
\text { 5. Kartu pasien masih menggunakan } \\
\text { kertas. Jika data pasien salah harus } \\
\text { menulis kembali dengan data pasien } \\
\text { yang benar. }\end{array}$ & $\begin{array}{l}\text { 1. Pasien tidak kesusahan mencari } \\
\text { kartu pasien karena dari aplikasi } \\
\text { sudah terdapat kartu pasien (profil } \\
\text { pasien) dan jika ada data yang } \\
\text { salah dapat diubah sendiri dengan } \\
\text { data yang benar. } \\
\text { 2. Melalui aplikasi antrian rawat } \\
\text { jalan, pengguna sudah dapat } \\
\text { melihat informasi jadwal praktek. } \\
\text { 3. Aplikasi ini terdapat informasi } \\
\text { kuota pasien pada jadwal praktek. } \\
\text { 4. Aplikasi ini lebih efisien untuk } \\
\text { daftar antrian rawat jalan karena } \\
\text { bisa daftar antri dimana saja secara } \\
\text { online. } \\
\text { 5. Aplikasi ini terdapat output nomor } \\
\text { antrian rawat jalan untuk bukti } \\
\text { pada klinik. } \\
\text { 6. Aplikasi terdapat output estimasi } \\
\text { waktu perjalanan agar pasien tahu } \\
\text { waktu yang dibutuhkan. }\end{array}$ \\
\hline
\end{tabular}

Tabel 3 menjelaskan perbandingan alur kerja jadwal antrian pasien secara manual dan sistem. Dengan adanya sistem jadwal antrian ini, pada sistem telah terdapat profil pasien, tentang kuota pasien pada saat itu, terdapat output nomor antrian rawat jalan berdasarkan keluhan pasien untuk dapat diprioritaskan dalam daftar antrian, mendapatkan informasi tentang daftar antrian dan estimasi waktu sehingga pasien dapat memperkirakan waktu perjalanan menuju klinik berobat. 


\section{KESIMPULAN dan SARAN}

\subsection{Kesimpulan}

Berdasarkan implementasi dan uji pengguna yang dilakukan pada aplikasi Antrian Rawat Jalan pada Klinik Pratama Berbasis Mobile dengan Metode Priority Scheduling dan First Come First Served Scheduling (FCFS), dapat diambil kesimpulan sebagai berikut :

1. Berdasarkan hasil pengujian aplikasi dari para pengguna, menggunakan metode Skala Likert diperoleh rata-rata $81,8 \%$, maka dapat disimpulkan bahwa aplikasi termasuk dalam kriteria "Sangat Baik".

2. Adanya aplikasi informasi jadwal praktek secara online ini, sangat bermanfaat bagi pengguna dan pengguna merasa puas.

3. Aplikasi ini lebih efisien dalam hal waktu untuk memperoleh nomer antrian rawat jalan dan dapat menghemat kertas.

4. Terdapat output nomor antrian rawat jalan berdasarkan keluhan pasien untuk dapat diprioritaskan dalam daftar antrian.

5. Terdapat output estimasi waktu sehingga pasien dapat memperkirakan waktu perjalanan menuju klinik berobat.

\subsection{Saran}

Adapun saran untuk pengembangan selanjutnya, sebagai berikut:

1. Perlu adanya penambahan peta GPS didalam aplikasi ini agar pengguna baru tahu tempat klinik pratama.

2. Perlu adanya penambahan meningkatkan keamanan pada website admin.

3. Perlu adanya estimasi waktu berangkat ke klinik yang lebih akurat.

\section{DAFTAR PUSTAKA}

[1]. Horton, J. 2015. Android Programming for Beginners. Packt Publishing Ltd.

[2]. B Hariyanto. 2002. System Operasi 5th edition. Penerbit Informatika.

[3]. Silberschatz, A., Galvin, P. B., \& Gagne, G. 2014. Operating system concepts essentials. John Wiley \& Sons, Inc.

[4]. Enterprise, J. 2015. Mengenal Dasar-Dasar Pemrograman Android. Elex Media Komputindo.

[5]. https://www.nesabamedia.com/pengertian-ftp/Diakses pada tanggal 01 Agustus 2018.

[6]. Sugiyono. 2008. Metode Penelitian Kuantitatif Kualitatif dan R\&D, Bandung Alfabeta.

[7]. Safaat, N. 2012. Pemrograman aplikasi mobile smartphone dan tablet pc berbasis android. Bandung: informatika.

[8]. Tata Sutabri. 2004. Analisa Sistem Informasi, Penerbit ANDI, Yogyakarta.

[9]. Preece, J., Rogers, Y., \& Sharp, H. 2015. Interaction design: beyond human-computer interaction. John Wiley \& Sons. 